\title{
Effects of ATRA combined with citrus and ginger- derived compounds in human SCC xenografts
}

Heather E Kleiner-Hancock ${ }^{1,6^{*}}$, Runhua Shi ${ }^{2,6}$, Angela Remeika ${ }^{1}$, Delira Robbins ${ }^{1}$, Misty Prince ${ }^{1}$, Jennifer N Gill ${ }^{3}$, Zanobia Syed ${ }^{3}$, Patrick Adegboyega ${ }^{4,6}$, J Michael Mathis ${ }^{5,6}$, John L Clifford ${ }^{3,6}$

\begin{abstract}
Background: NF- $\kappa \mathrm{B}$ is a survival signaling transcription factor complex involved in the malignant phenotype of many cancers, including squamous cell carcinomas (SCC). The citrus coumarin, auraptene (AUR), and the ethnomedicinal ginger (Alpinia galanga) phenylpropanoid, 1'-acetoxychavicol acetate (ACA), were previously shown to suppress 12-0-tetradecanoylphorbol-13-acetate (TPA) induced mouse skin tumor promotion. The goal of the present study was to determine whether AUR and ACA are effective either alone or in combination with all-trans retinoic acid (ATRA) for suppressing SCC tumor growth.

Methods: We first determined the effects of orally administered ACA (100 mg/kg bw) and AUR (200 mg/kg bw) on lipopolysaccharide (LPS)-induced NF- $\kappa$ B activation in NF- $\kappa$ B-RE-luc (Oslo) luciferase reporter mice. Dietary administration of AUR and ACA \pm ATRA was next evaluated in a xenograft mouse model. Female SCID/bg mice were fed diets containing the experimental compounds, injected with $1 \times 10^{6}$ SRB12-p9 cells s.c., palpated and weighed twice a week for 28 days following injection.

Results: Both ACA and AUR suppressed LPS-induced NF- $\kappa$ B activation in the report mice. In the xenograft model, AUR (1000 ppm) and ACA (500 ppm) modestly suppressed tumor volume. However, in combination with ATRA at 5, 10, and 30 ppm, ACA 500 ppm significantly inhibited tumor volume by $56 \%, 62 \%$, and $98 \%$, respectively. The effect of ATRA alone was 37\%, 33\%, and 93\% inhibition, respectively. AUR $1000 \mathrm{ppm}$ and ATRA $10 \mathrm{ppm}$ were not very effective when administered alone, but when combined, strongly suppressed tumor volume by $84 \%$.
\end{abstract}

Conclusions: Citrus AUR may synergize the tumor suppressive effects of ATRA, while ACA may prolong the inhibitory effects of ATRA. Further studies will be necessary to determine whether these combinations may be useful in the control of human SCC.

\section{Background}

Non-melanoma skin cancer (NMSC) is the most common cancer in the U.S., with over a million new cases of the two most common forms, squamous cell carcinoma (SCC) and basal cell carcinoma (BCC), anticipated annually [1]. The more clinically aggressive form is SCC of the skin [2], which has been increasing in incidence since the $1960 \mathrm{~s}$ at annual rates from $4 \%$ to as much as $10 \%$ in recent years. Better control of advanced skin SCC is clearly necessary, and will be helped by improving our understanding of the molecular basis for skin

\footnotetext{
* Correspondence: hklein@lsuhsc.edu
'Department of Pharmacology, Toxicology \& Neuroscience, Louisiana State

* Correspondence: hklein@lsuhsc.edu
'Department of Pharmacology, Toxicology \& Neuroscience, Louisiana State University Health Sciences Center-Shreveport, 1501 Kings Hwy, Shreveport, Louisiana, 71103 USA
}

(c) 2010 Kleiner-Hancock et al; licensee BioMed Central Ltd. This is an Open Access article distributed under the terms of the Creative Commons Attribution License (http://creativecommons.org/licenses/by/2.0), which permits unrestricted use, distribution, and reproduction in any medium, provided the original work is properly cited.

carcinogenesis and of the action of chemopreventive drugs.

Nuclear factor $\kappa \mathrm{B}(\mathrm{NF}-\kappa \mathrm{B})$ is activated during inflammation and carcinogenesis [3]. Lipopolysaccharide (LPS), interleukin-1 $\beta$, hydrogen peroxide, and tumor necrosis factor activate NF- $\kappa \mathrm{B}$ signaling through phosphorylation of its inhibitor $\mathrm{I} \kappa \mathrm{B} \alpha$. This leads to degradation of $\mathrm{I} \kappa \mathrm{B} \alpha$, phosphorylation of the p $65 \mathrm{NF}-\kappa \mathrm{B}$ subunit, and translocation of p65, along with the p50 subunit, to the nucleus. There they form a DNA binding complex and activate transcription of specific genes involved in proliferation (cyclin D1, c-myc, COX-2), angiogenesis (vascular endothelial growth factor-VEGF), antiapoptosis (survivin, TRAF1, IAP1, BclXL, FLIP) and invasion (matrix metalloproteinase 9, ICAM-1) [4].

\section{Biomed Central}


1'-acetoxychavicol acetate (ACA) is a natural component of traditional Thai condiments, present in the seeds (15000 ppm) and rhizomes (27300 ppm) of the ethnomedicinal plant Languas galanga Stuntz (Zingiberaceae) [5]. In the skin model, pre-treatment of mice with ACA prior to TPA treatment in 7,12-dimethylbenz [a] anthracene (DMBA)-initiated mice suppressed skin tumor promotion [6]. Recently it was found that ACA blocked TNF- $\alpha$ induced activation of NF- $\kappa \mathrm{B}$ indirectly through $\mathrm{I} \kappa \mathrm{B}$ [7]. In this regard, ACA inhibited TNF- $\alpha$ induced phosphorylation and degradation of $\mathrm{I} \kappa \mathrm{B} \alpha$, suggesting that it inhibits the $\mathrm{I} \kappa \mathrm{B} \alpha$ kinase, IKK. Auraptene (AUR) is a geranyloxy-coumarin obtained from citrus fruits [8], the aromatic plant Zanthoxylum schinifolium [9] and the fruits of Paliurus ramosissimus [10]. AUR is also known to suppress skin tumor promotion [8], in addition to its many other chemopreventive effects. AUR suppresses superoxide generation indirectly, most likely through inhibition of the multi-component NADPH oxidase system [8]. AUR, possessing antiinflammatory activities [11] also suppresses ulcerative colitis and ulcerative colitis induced colon cancer $[12,13]$. Consistent with these observations, AUR also activated PPAR $\gamma$ in adipocytes, which led to the increased production of adiponection, which is known to suppress the inflammatory process [14]. These varied mechanisms and protective effects in rodent models of cancer, combined with the low risk of toxicity [15], suggest that AUR might be a good candidate for skin SCC chemoprevention.

Retinoids are a class of chemical compounds, which include active metabolites of vitamin A (retinol), as well as a diverse array of synthetic derivatives. Retinoids have been shown to modulate multiple cellular processes, including proliferation, differentiation, homeostasis, malignant transformation and apoptosis [16-18]. ATRA has long been known as one of the most effective suppressors of tumor formation in the 2-stage mouse skin chemical carcinogenesis model $[19,20]$. We have recently used this model to further explore the mechanism of ATRA action and have demonstrated that ATRA targets the B-Raf/Mek/Erk signaling pathway and this activity coincides with its chemopreventive activity [21]. We have also shown recently that ATRA can suppress Stat3 signaling in skin carcinogenesis, and that Stat3 activity lies downstream of the B-Raf/Mek/Erk pathway [22]. It is interesting to note that many downstream signaling effectors involved in malignancy are regulated by both Stat 3 and NF- $\kappa$ B

We hypothesized that suppression of both B-Raf/ Mek/Erk/Stat3 and NF- $\kappa$ B signaling through combined administration of ATRA and ACA/AUR, may exert a stronger anti-tumor effect than either agent alone.

\section{Methods}

\section{Cell culture}

The human skin SCC cell line SRB12-p9 was derived by single cell cloning from SRB12 cells (a gift from Dr. Reuben Lotan, Department of Thoracic Head and Neck Medical Oncology, University of Texas M.D. Anderson Cancer Center). Cells were cultured in a humidified atmosphere at $5 \% \mathrm{CO}_{2}$, in Dulbecco's Modified Eagle's Media-F12 supplemented with $10 \%$ fetal bovine serum.

\section{Severe combined immunodeficient (SCID) beige mice}

$\mathrm{SCID} / \mathrm{bg}$ mice were housed sterile cages in a temperature and humidity controlled AAALAC facility under a normal 12 hour light/dark cycle. All procedures were approved by LSUHSC Institutional Animal Care and Use Committee in accordance with $\mathrm{NIH}$ guidelines. The mice were allowed access to autoclaved food and water ad libitum.

\section{NF- $\kappa$ B-RE-luc (Oslo) mice}

All mice were allowed food and water ad libitum and were housed according to institutional and NIH guidelines. Mice were purchased from the Xenogen Corporation (Alameda, California) and are bred and genotyped in our breeding colony. $N F-\kappa B-R E-l u c$ is a light producing animal model that carries a transgene containing 3 $\mathrm{NF}-\kappa \mathrm{B}$ response elements from the Ig $\kappa$ light chain promoter and modified firefly luciferase cDNA (Promega pGL-3) [23]. The reporter is expressed under basal conditions in the lymph node (neck), thymus (thoracic region), and Peyer's patches (abdominal region). Various inflammatory stimuli induce the reporter, such as LPS, TNF- $a$, and arthritis, which makes it suitable for the study of transcriptional regulation of NF- $\kappa \mathrm{B}$. Male and female mice $(n=3-4)$ were pre-treated with ACA (100 $\mathrm{mg} / \mathrm{kg} \mathrm{bw})$, AUR $(200 \mathrm{mg} / \mathrm{kg} \mathrm{bw})$ or vehicle $(0.2 \mathrm{~mL}$ corn oil/25 g bw) once a day for 4 consecutive days. At $30 \mathrm{~min}$ after the last pretreatment, mice were injected with LPS $(2.7 \mathrm{mg} / \mathrm{kg}$ bw). Mice were imaged on an IVIS 100 Imaging System at $30 \mathrm{~min}$ after the $3^{\text {rd }}$ pre-treatment dose as a pre-screen to ensure that the pre-treatments themselves did not activate NF- $\kappa \mathrm{B}$. Mice were imaged again at $3 \mathrm{~h}$ and $24 \mathrm{~h}$ after LPS treatment. Mice were injected with $2.5 \mathrm{mg}$ D-luciferin substrate, along with ketamine/xylazine anesthetic, 15 minutes prior to each imaging. Luminescence intensity was quantified using Living Image (R) 3.0 software (Caliper Life Sciences, Inc., Hopkinton, MA).

\section{Xenograft Model}

Groups of 5-8 female SCID/bg mice (6-12 weeks of age) each were fed control diets or diets containing ATRA (5, 10, $30 \mathrm{ppm})$, ACA (500 ppm) or AUR (1000 ppm) or 
ATRA + ACA/AUR, starting 1 week prior to tumor cell inoculation and for the duration of the study. Test diets were administered prior to the injection of tumor cells to be a chemoprevention protocol. In humans, this might be applicable to individuals who have been treated for a primary tumor, but are susceptible to the development of subsequent tumors. This could be a window of opportunity for chemoprevention. Mice were shaved (2 days prior to injection), then injected with $1 \times$ $10^{6}$ SRB12-p9 cells suspended in sterile PBS, s.c., palpated and weighed twice a week for 25-28 days following injection. Tumors were measured using digital calipers and tumor volume $\left(\mathrm{mm}^{3}\right)$ was calculated using the following formula, based on the assumption of a near-spherical tumor shape: $\mathrm{V}=((l+w) / 4)^{3} * 1.33 * \mathrm{PI}$, where $l=$ length, $w=$ width. The studies were conducted at different times, so the timing was kept to a 25-28 day window for consistency. All mice in a particular study were euthanized on the same day so that comparisons could be made.

\section{microPET imaging}

Tumor bearing mice were investigated by non-invasive imaging using a R4 microPET scanner (Siemens Medical Solutions USA, Inc., Knoxville, TN). In brief, the system operates in three dimensions and is composed of 6144 lutetium oxyorthosilicate crystal (LSO) detector elements, with a $7.8 \mathrm{~cm}$ axial and a $10 \mathrm{~cm}$ transaxial fieldof-view. The [18F]-3'-fluoro-3'-deoxy-L-thymidine ([18F] FLT) radiotracer, a pyrimidine nucleoside analogue, has been validated as a promising PET radiopharmaceutical for monitoring tumor proliferation as well as response to therapy [24]. The [18F]FLT was synthesized using a 3-N-Boc-5'-O-dimethoxytrityl-3'-O-nosyl-thymidine precursor according to published method of Eisenhut et al. [25]. No-carrier-added [18F]FLT was administered intravenously by tail vein injection into experimental animals at a dose of $300 \mathrm{mCi} /$ mouse. Sixty minutes after injection, the animals were anesthetized, positioned in the field of view of the scanner, and imaged for 15 minutes. Subsequently, the microPET images were reconstructed using an iterative reconstruction technique.

\section{Glutathione S-transferase (GST) and NAD(P)H quinone oxidoreductase (NQO) activities}

Liver cytosolic GST activities were assayed spectrophotometrically (Shimadzu, Columbia, MD, kinetic mode) using two different substrates [26]. First, liver cytosol enriched fractions were prepared by differential centrifugation as previously described [27]. Protein concentrations were estimated using the Bradford method with BSA as a standard [28]. Aliquots of cytosolic samples were incubated with either $1 \mathrm{mM} \mathrm{1,2-dichloro-4-}$ nitrobenzene (DCNB), $5 \mathrm{mM} \mathrm{GSH}$ in $0.1 \mathrm{M}$
KH2PO4 buffer, pH 7.5; or with $1 \mathrm{mM} 1$-chloro2,4-dinitrobenzene (CDNB), $1 \mathrm{mM} \mathrm{GSH,} \mathrm{in}$ $0.1 \mathrm{M} \mathrm{KH} 2 \mathrm{PO} 4$ buffer, $\mathrm{pH}$ 6.5. Changes in absorbances were assessed at $340 \mathrm{~nm}$ (CDNB) or $345 \mathrm{~nm}$ (DCNB), and enzyme activities were calculated using extinction coefficients of $9.6 \mathrm{nM}^{-1} / \mathrm{cm}^{-1}$ and $8.5 \mathrm{nM}^{-1}$ / $\mathrm{cm}^{-1}$, respectively [29]. Liver cytosolic NQO activity was assayed spectrophotometrically (kinetic mode) at 600 $\mathrm{nm}$ using 2,6-dichloroindophenol $(1.25 \mathrm{mM})$ as a substrate and an extinction coefficient of $21 \mathrm{nM}^{-1} / \mathrm{cm}^{-1}$ as previously described [30].

\section{Statistical analysis}

For NF- $\kappa \mathrm{B}$ and GST data, differences between groups were compared using ANOVA followed by post-hoc analysis with Fisher's PLSD test and/or Tukey's test. Group comparisons are shown in the figure and table legends. Descriptive statistics of body weight and tumor volume were presented as means and least squared means along with standard deviation and sample size for a particular sub-group. Analysis of variance method was used to compare the body weight and tumor volume among groups (ACA, AUR and ATRA). Subsequently, the multiple comparison using Dunnett method was made among the group (all other group compares to control group). To perform the non-parametric data analysis, the body weight and tumor volume were ranked first and then similar analysis were performed as described above. A linear trend test was performed to assess the effect of ATRA dosage of 0, 5, 10, and 30 with/without ACA on the body weight and tumor volume at particular days $(13,15,20$, and 22) after treatment. Only these days have the same measurement for the dosage of ATRA, the number of mice in the control dosage level (0) were combination of two separated experiment in this study $(\mathrm{n}=13)$, the number of mice are 8,8 , and 5 for dose level of 5,10 and 30 . All pvalues, $\leq 0.05$ were considered statistically significant. All statistical data analysis was performed by using SAS system 9.2 (SAS Inc, Gary, NC).

\section{Results}

ACA and AUR suppressed LPS-induced NF- $\kappa$ B activation in NF- $\kappa$ B-RE-luc (Oslo) mice

Many phytochemicals suppress NF- $\kappa \mathrm{B}$ activation, so we used a simple in vivo method using NF- $\kappa B-R E-l u c$ (Oslo) to first determine whether ACA and AUR also possessed this inhibitory activity. Male and female mice ( $\mathrm{n}=3-4)$ were pre-treated with ACA $(100 \mathrm{mg} / \mathrm{kg} \mathrm{bw})$, AUR $(200 \mathrm{mg} / \mathrm{kg} \mathrm{bw})$ or vehicle $(0.2 \mathrm{~mL}$ corn oil $/ 25 \mathrm{~g}$ bw) once a day for 4 consecutive days. On day 3 , mice were imaged as a pre-screen to ensure that ACA and AUR did not activate the NF- $\kappa \mathrm{B}$ reporter. On day 4 , $30 \mathrm{~min}$ after the last pretreatment, mice were injected 

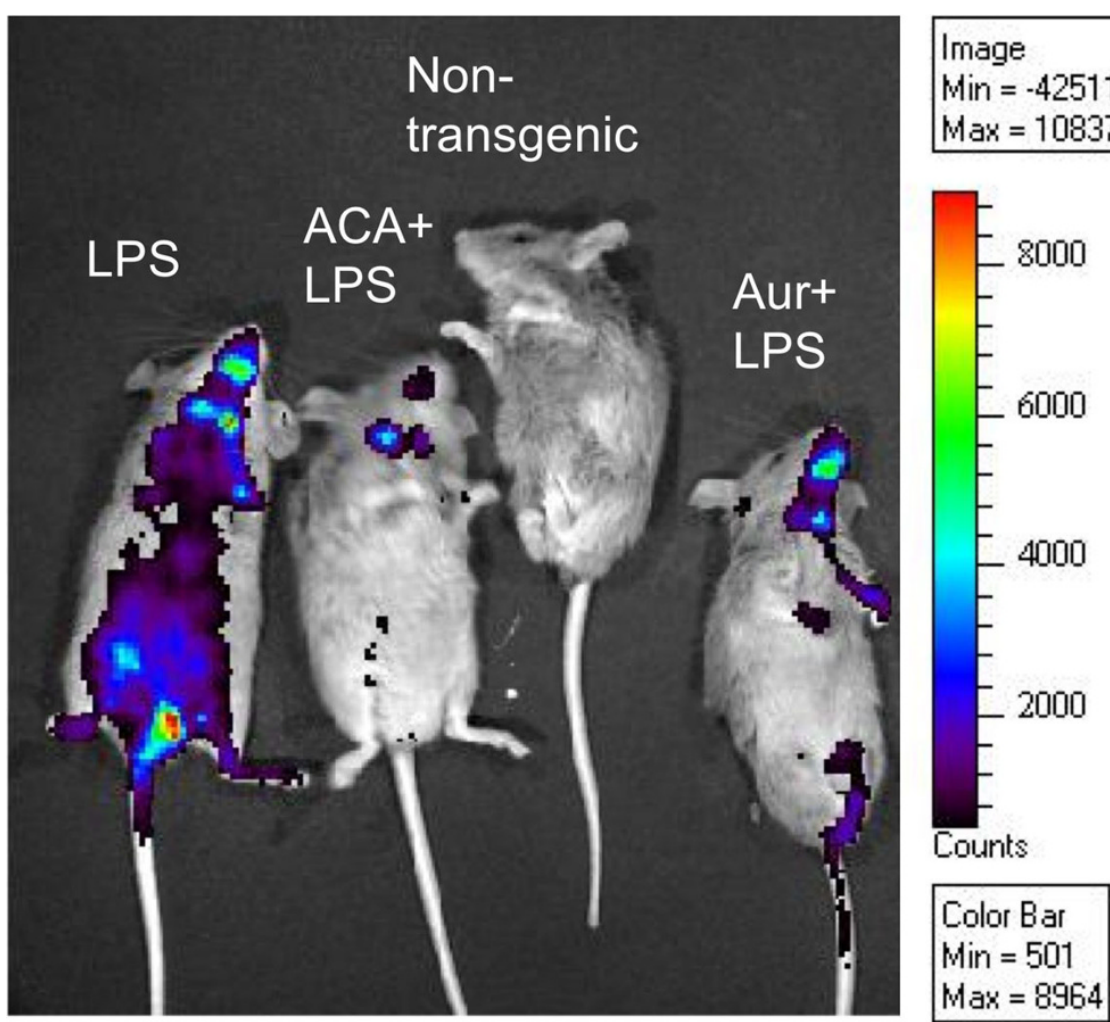

Figure 1 ACA and AUR suppress LPS-induced NF- $\kappa$ B activation in NF- $\kappa$ B-RE-luc (Oslo) mice. Picture depicts live animal imaging of luciferase.

with LPS ( $2.7 \mathrm{mg} / \mathrm{kg} \mathrm{bw})$ and imaged $3 \mathrm{~h}$ and $24 \mathrm{~h}$ after LPS treatment, as described in materials and methods. Mice dosed with LPS expressed a significant increase in NF- $\kappa$ B luciferase at $3 \mathrm{~h}$ after LPS (Figures 1, 2). Both ACA and AUR significantly inhibited NF- $\kappa$ B luciferase expression by $65 \%$ and $76 \%$, respectively at $3 \mathrm{~h}$ after LPS (Figure 2). There was very little luciferase expression at the pre-screen time point, confirming that the pre-treatments did not activate NF- $\kappa$ B. By $24 \mathrm{~h}$, the expression of luciferase declined and there were no significant differences in any of the treatment groups.

ACA and ATRA suppression of skin SCC tumor growth: A potentially beneficial combination

Previous data generated by our groups and others suggests that ATRA and ACA suppress Stat 3 and NF- $\kappa$ B activation, respectively $[7,22]$. As both pathways have been shown to be important in the development of various cancers including skin SCC, we hypothesized that the simultaneous suppression of each pathway using ATRA + ACA would be more effective than using either agent alone at suppressing SCC growth. To address this hypothesis, female SCID/bg mice were inoculated with 1 $\times 10^{6}$ SRB12-p9 cells and weighed and their tumors were measure by digital calipers over the course of 25 days. Groups of 5-8 mice each were fed control diets or diets containing ATRA (5, 10, and 30 ppm), ACA (500 ppm), or ATRA + ACA, starting 1 week prior to tumor cell inoculation and for the duration of the study. The dose of ACA was selected based on its activity in previous dietary studies [31-34]. Tumor volume increased

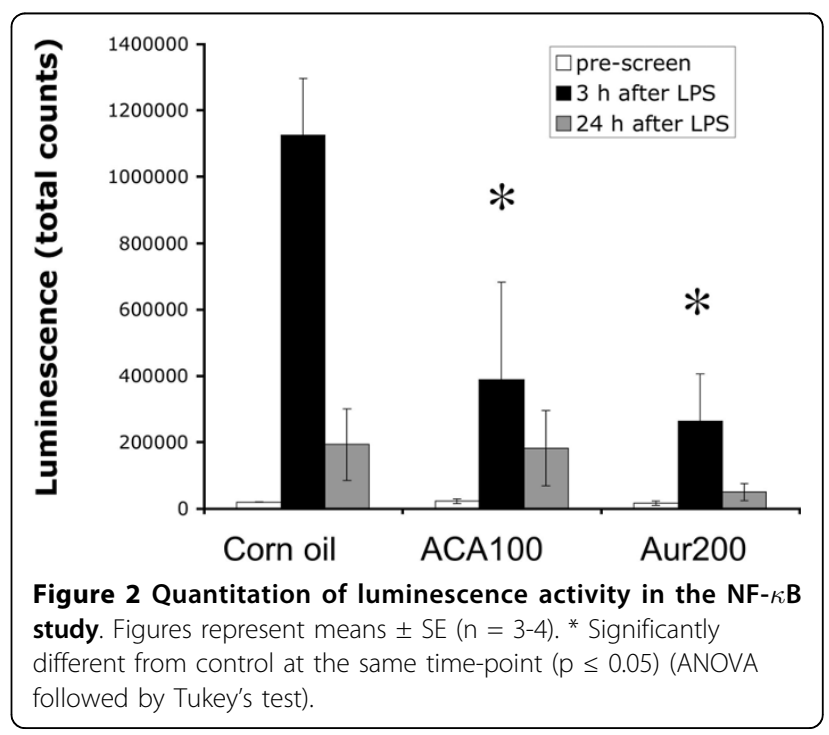


rapidly at day 15 to day 25 after inoculation in the control diet groups, reaching a maximum of $650-875 \mathrm{~mm}^{3}$. ACA had a marginally significant effect on tumor volume between days 18-22 (Figures 3A, B) and [Additional file 1: Supplemental Tables S1, S2]. Dietary ATRA (5 ppm) modestly suppressed tumor volume but not significantly [Additional file 1: Supplemental Tables S1, S2]. Comparing both parametric and non-parametric analyses, the combination of 5 ppm ATRA and ACA in the diet significantly inhibited tumor volume starting at 11 days and continuing throughout the study, ranging from 56-76\% inhibition [Additional file 1: Supplemental Tables S1, S2]. 10 ppm ATRA modestly inhibited tumor volume from $45-58 \%$ starting at day 11 up to day 22 , but its effects were marginally significant - significant for a few days [Additional file 1: Supplemental Tables S1, S2]. The combination of $10 \mathrm{ppm}$ ATRA and ACA significantly suppressed tumor volume by $50-67 \%$ starting at day 11 to day 25, again comparing both parametric and non-parametric analyses [Additional file 1: Supplemental Tables S1, S2]. In the $30 \mathrm{ppm}$ ATRA experiment, ACA did not exhibit any significant effects on its own, although there was a $51 \%$ inhibition of tumor volume at day 23 that was not statistically significant. A lower number of subjects (5 mice instead of 78 ) in this experiment likely contributed to this lack of statistical significance, compared to the 5 and $10 \mathrm{ppm}$ ATRA studies. However, 30 ppm ATRA strongly suppressed tumor volume by $70-93 \%$ from day 9 to day 23, and the combination of ATRA 30 with ACA significantly suppressed tumor volume from $89-98 \%$ (Figure 3C) and [Additional file 1: Supplemental Tables S1, S2]. Body weight analyses demonstrated a significant change in the ATRA 5 and 30 groups, for most time-points [Additional file 1: Supplemental Table S3]. However, dose-response analyses suggested that the effect was independent of ACA [Additional file 1: Supplemental Table S5]. Dose-response analyses of ATRA 5, 10, and

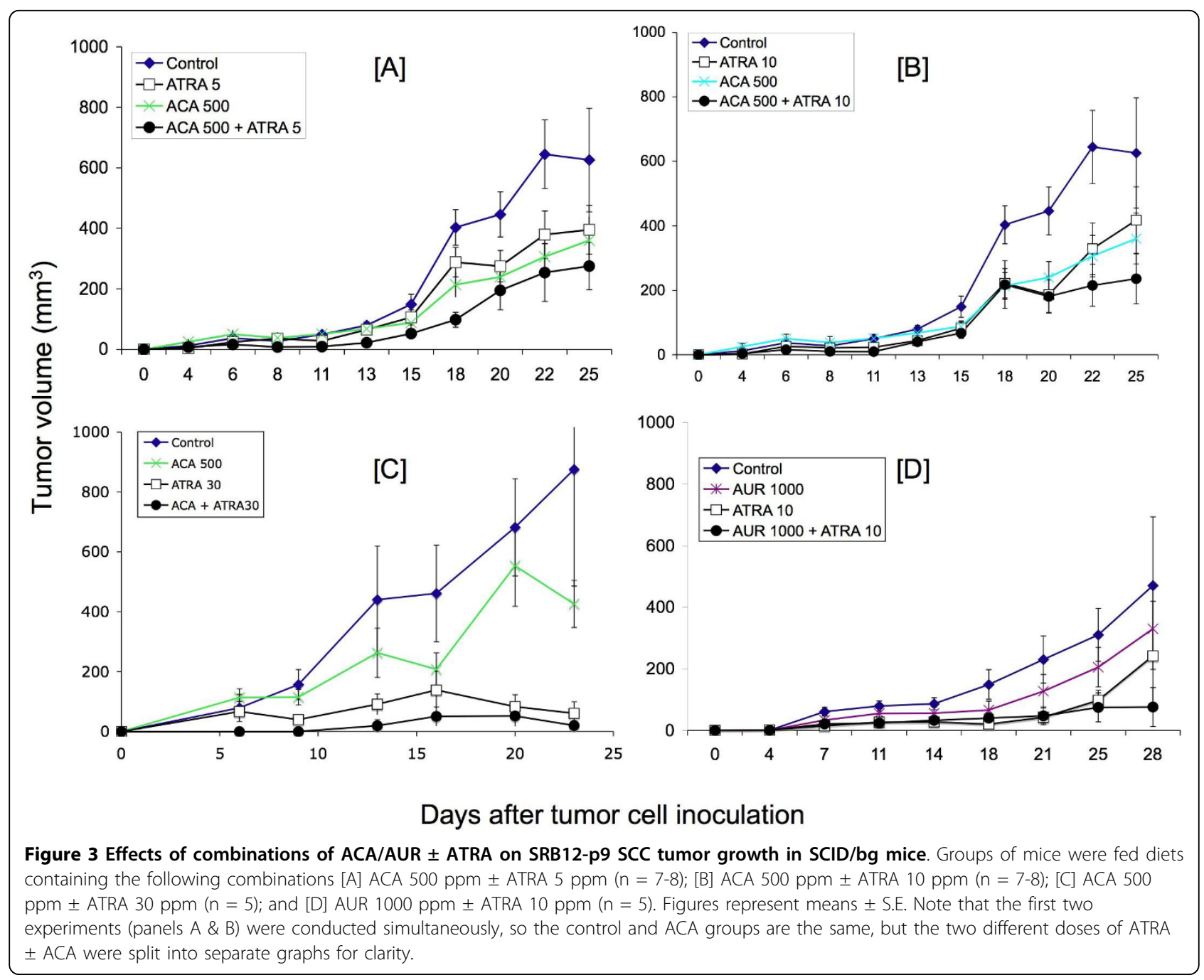


$30 \mathrm{ppm} \pm$ ACA demonstrated relatively similar levels of significance, suggesting the effect on tumor volume was dependent on dose of ATRA [Additional file 1: Supplemental Table S4]. A linear trend analysis supported this observation [Additional file 1: Supplemental Table S6]. Live animal imaging (FLT) of representative mice from the 30 ppm ATRA combination study are shown in Figure 4. Sagittal sections through the tumor indicated that the size of tumors visualized in live mice corresponded with the values obtained from caliper measurements.
AUR and ATRA suppression of skin SCC tumor growth: Another potentially beneficial combination

We next tested the AUR + ATRA combination in the skin SCC xenograft model. As shown in Figure 3D and [Additional file 1: Supplemental Table S7], treatment with AUR (1000 ppm in the diet) alone did not reduce tumor volume to a statistically significant level. $10 \mathrm{ppm}$ ATRA, as observed in the first set of studies, significantly inhibited tumor volume by $49-87 \%$ starting at day 7 and continuing throughout the study (Figure 3D) and
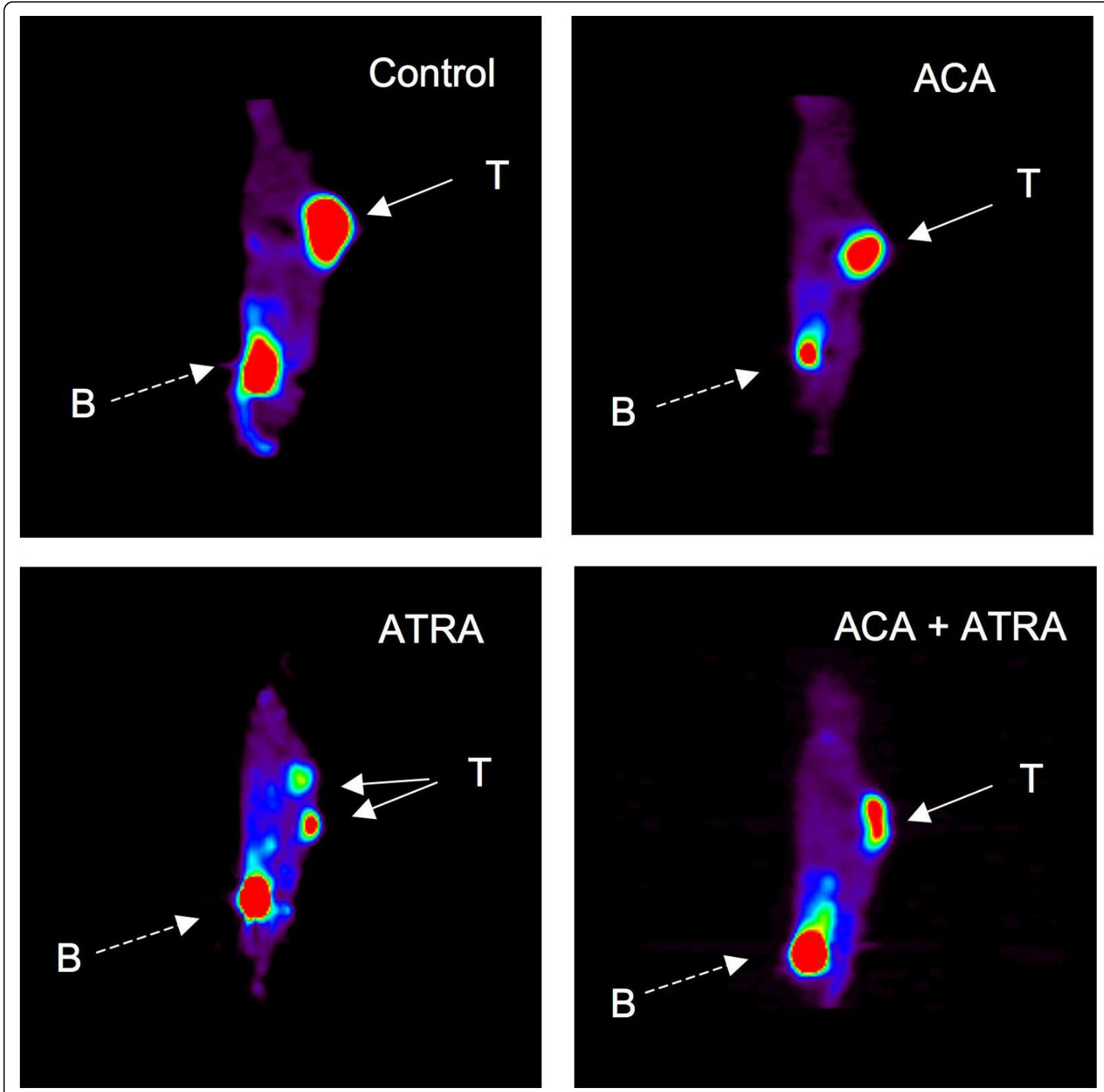

Figure 4 Representative FLT-PET live animal imaging from the ACA $500 \pm$ ATRA $\mathbf{3 0}$ study. Solid arrows marked with "T" point to the tumors, and dashed arrows marked with " $B$ " point to the urinary bladder, where the isotope is eliminated. 
[Additional file 1: Supplemental Table S7]. The combination of AUR + 10 ppm ATRA also significantly inhibited tumor volume by $62-84 \%$ starting at day 7 and continuing until day 25. At day 28, the combination of ATRA + AUR suppressed tumor volume by $84 \%$, although the results were not statistically significant at this date. Photos of tumors from representative mice illustrate this strong combination effect (Figure 5). Statistical analysis of body weights showed a modest reduction in body weights in the ATRA treated groups [Additional file 1: Supplemental Table S8].

Our laboratory and others have shown that one of the chemopreventive activities of AUR is induction of phase II detoxifying enzymes through activation of the Nrf-2/ antioxidant response element $[35,36]$. In the current study, we also assessed whether the combination of AUR and ATRA maintained this effect. As shown in Table 1, AUR significantly induced GST activities using DCNB as a substrate. No significant effects on NQO activities or on GST activities using CDNB as a substrate were observed. CDNB is a more general substrate for GST activities [37], hence may have diluted out any specific effects of AUR at the dietary exposure level in the current study. Also, we have previously observed that AUR is also not a very strong inducer of hepatic
Table 1 Effects of dietary combinations of AUR and ATRA on NQO1 and GST activities.

\begin{tabular}{llll}
\hline Diet & NQO1 & CDNB * 1000 & DCNB * 1000 \\
\hline Control & $3.17 \pm 0.27$ & $316 \pm 36$ & $14.9 \pm 2.0$ \\
AUR & $4.09 \pm 0.30$ & $371 \pm 47$ & $27.5 \pm 0.7^{* *}$ \\
ATRA & $3.01 \pm 0.50$ & $371 \pm 34$ & $18.3 \pm 1.5$ \\
AUR + ATRA & $4.27 \pm 0.57$ & $386 \pm 16$ & $18.8 \pm 1.6$ \\
\hline
\end{tabular}

** Significantly different from control diet ( $p<0.01$, Tukey's test)

Figures represent mean activities ( $\mu \mathrm{mol} / \mathrm{min} / \mathrm{mg}$ protein $) \pm \mathrm{SE}(n=4-5)$.

NQO activity [35], so these results are not surprising. However, it appeared that ATRA itself might have modestly increased GST activity, and the combination of AUR and ATRA did not afford any increase in activity (using DCNB as a substrate) compared to ATRA alone, and no statistically significant increase compared to the vehicle control group. Thus ATRA may slightly inhibit the GST inducing effect of AUR.

\section{Discussion}

Taken together, the current studies have demonstrated that ACA and AUR suppressed LPS-induced activation of NF- $\kappa \mathrm{B}$ in NF- $\kappa B-R e-l u c$ mice, and modestly inhibited SRB12-p9 tumor growth in the xenograft model. Although ATRA was fairly effective at doses as low as

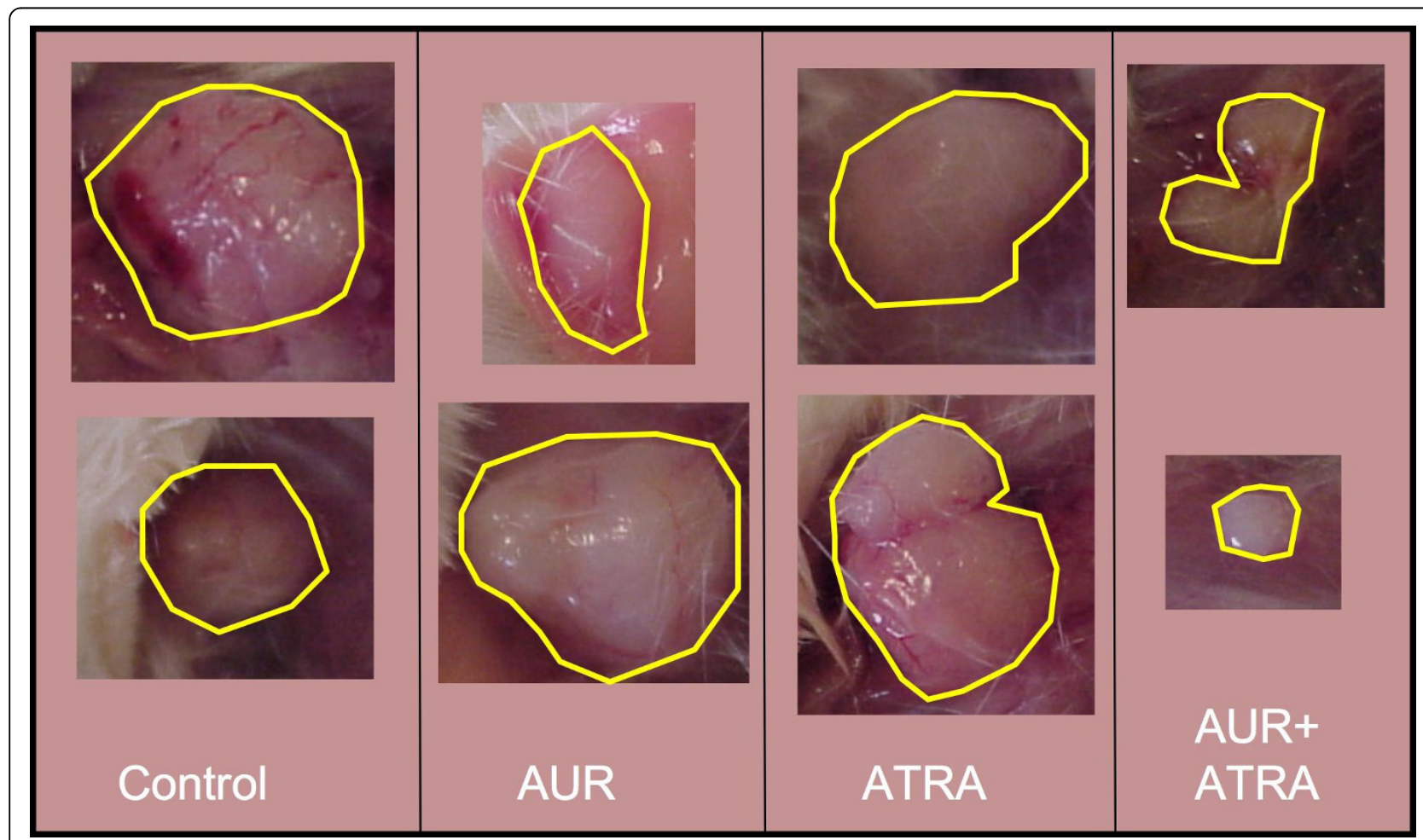

Figure 5 Representative tumors from the Auraptene $1000 \pm$ ATRA 10 study. Photographs were taken from duplicate mice in each group. Lines were drawn around the tumor margins for clarity. 
$10 \mathrm{ppm}$ in the diet, the inhibitory effect can be maintained to the end of the study when combined with either ACA or AUR. Although neither ACA nor AUR possessed strong inhibitory effects on their own, these data suggest that they may be useful in combination with ATRA. This is particularly important because ATRA is known to produce hypervitaminosis A-related side effects, and if its dose can be limited and efficacy improved by combining with naturally occurring dietary agents, these combinations could be clinically useful. However, diets containing ATRA led to a dose-related decrease in body weights, which was not different when combined with ACA or AUR.

Many other phytochemicals are known to suppress NF- $\kappa \mathrm{B}$ activation [38]. Among these, several are related to the Zingiberaceae family, including gingerol and curcumin. These agents have been known to suppress many types of cancer, including that of skin. Taken together, these data lend to an intriguing suggestion that suppression of NF- $\kappa \mathrm{B}$ activation in combination with suppression of the B-raf/Mek/Erk/Stat3 pathway may be a useful strategy in the suppression of cancer progression. Many downstream signaling effectors involved in malignancy are regulated by both Stat 3 and $\mathrm{NF}-\kappa \mathrm{B}$, such that targeting both of these signaling pathways at once by combining ATRA + AUR, may produce a synergistic tumor suppressive effect. New evidence is also helping to decipher the connections between NF$\kappa \mathrm{B}$ and STAT3. In 2007, Yang and associates discovered that unphosphorylated STAT3 competes with IKB for binding to unphosphorylated NF- $\kappa \mathrm{B}$. This is turn results in nuclear localization of this complex, leading to activation of NF- $\kappa \mathrm{B}$ regulated genes [39]. Most recently, Lee and co-workers demonstrated that STAT3 impairs nuclear export of NF- $\kappa \mathrm{B}$ via activation of RelA acetylation [40]. Thus it appears that STAT3 may enhance the effects of NF- $\kappa$ B through multiple mechanisms.

The combinatorial effects of ATRA and AUR were encouraging. AUR is known to activate Nrf2/ARE and induces carcinogen and oxidant-detoxifying enzymes. However, recently, a "dark side" of Nrf2 has been suggested: that Nrf2 is upregulated in cancer (particularly lung cancer) and provides cancer cells with protection against the hostile tumor microenvironment [41]. In fact, shRNA against Nrf2 in lung cancer cells attenuated their growth in mouse xenografts compared to vector control treated cells [42]. It is argued that chemopreventive agents that increase Nrf2 activity may produce chemoresistance to therapy [43]. However, Wang and colleagues demonstrated that ATRA reduced binding of Nrf2 to the ARE enhancer [42]. ATRA has been reputed to possess pro-oxidant activities at therapeutic concentrations. If it suppresses Nrf2 activation it may render cells more susceptible to oxidative stress. In fact, Tan and colleagues confirmed that ATRA activates the Nrf2/ ARE transcription pathway [44]. Although beyond the scope of the present study, it appears that perhaps ATRA behaves in combination with AUR as a partial agonist: that is, ATRA has a mild effect on activating Nrf2 by itself, but is milder than AUR, and in combination, may mitigate the effects of AUR, leading to an intermediate effect on Nrf2/ARE. Considering the potentially controversial role of Nrf2/ARE in carcinogenesis, we believe that the combination of ATRA with AUR for cancer therapy is even more enticing, because both agents were shown to be more effective at suppressing tumor growth in combination, despite the apparently intermediate effect on Nrf2/ARE.

\section{Conclusions}

In conclusion, we report that the combination of two different phytochemicals, ACA and AUR in the diet, enhanced the chemoprotective effect of ATRA against human skin cancer cell growth in a xenograft model. In particular, AUR appeared to be synergistic with the effects of ATRA, whereas ACA appeared to prolong the tumor suppressive effects of ATRA. We believe these mechanisms to be related to the suppression of at least two pathways, Stat 3 and NF- $\kappa$ B. Future studies may be warranted to capitalize on using these combinations to target multiple oncogenic pathways to enhance efficacy and lower potential off-target effects.

\section{Additional material}

Additional file 1: Supplemental Table S1. $2 \times 2$ Factorial design for statistical analyses. Supplemental Table S2. Tumor volume (TV) statistics for ACA \pm ATRA xenograft study. Supplemental Table S3. Body weight (BW) statistics for ACA \pm ATRA xenograft study. Supplemental Table S4: Tumor volume (TV) as a function of ATRA dose: statistics for ACA \pm ATRA xenograft study. Supplemental Table S5: Body weight (BW) statistics for ACA \pm ATRA xenograft study as a function of ATRA dose. Supplemental Table S6: Trend effect of ATRA dose in presence or absence of ACA on tumor volume (TV). Supplemental Table S7: Tumor volume (TV) statistics for AUR \pm ATRA study. Supplemental Table S8: Body weight (BW) data for AUR \pm ATRA study.

\section{Abbreviations}

ACA: 1'-acetoxychavicol acetate; ARE: antioxidant response element; ATRA: all-trans retinoic acid; AUR: auraptene; CDNB: 1-chloro-2, 4-

dinitrobenzene; DCNB: 1,2-dichloro-4-nitrobenzene; GST: glutathione S-transferase; LPS: lipopolysaccharide; NF- $\kappa$ B: nuclear factor kappa-B; NMSC: nonmelanoma skin cancer; NQO: NAD(P)H quinone oxidoreductase; SCC: Squamous cell carcinoma; SCID: severe combined immunodeficiency; TPA: 12-O-tetradecanoylphorbol-13-acetate.

\section{Acknowledgements}

The authors gratefully acknowledge the expert technical assistance of Tracee Terry, in the Small Animal Imaging Center. This research was supported in part by grants from the Feist-Weiller Cancer Center and the Department of Pharmacology, Toxicology \& Neuroscience. This research was also supported, in part, by a National Cancer Institute grant 1K22CA102005-01A2 (HEK) and 
1R21CA116324 (JLC). The content is solely the responsibility of the authors and does not necessarily represent the official views of the National Cancer Institute or the National Institutes of Health. Ms. Remeika was supported by the Summer Undergraduate Pharmacology Experience in Research (SUPER) program, which received funding from the American Society for Pharmacology and Experimental Therapeutics (ASPET) Summer Undergraduate Research Fellowship (SURF), the LSU Health Sciences Foundation, and the Department of Pharmacology, Toxicology, and Neuroscience.

\section{Author details}

${ }^{1}$ Department of Pharmacology, Toxicology \& Neuroscience, Louisiana State University Health Sciences Center-Shreveport, 1501 Kings Hwy, Shreveport, Louisiana, 71103 USA. ²Department of Medicine, Louisiana State University Health Sciences Center-Shreveport, 1501 Kings Hwy, Shreveport, Louisiana, 71103 USA. ${ }^{3}$ Department of Biochemistry and Molecular Biology, Louisiana State University Health Sciences Center-Shreveport, 1501 Kings Hwy, Shreveport, Louisiana, 71103 USA. ${ }^{4}$ Department of Pathology, Louisiana State University Health Sciences Center-Shreveport, 1501 Kings Hwy, Shreveport, Louisiana, 71103 USA. ${ }^{5}$ Department of Cellular Biology \& Anatomy, Louisiana State University Health Sciences Center-Shreveport, 1501 Kings Hwy, Shreveport, Louisiana, 71103 USA. ${ }^{6}$ Center for Experimental Cancer Therapeutics, Cancer Prevention \& Control Group, Feist-Weiller Cancer Center, 1501 Kings Hwy, Shreveport, LA, 71103 USA.

\section{Authors' contributions}

The research team was directed equally by HK and JC. HK and MJM carried out the NF- $\kappa$ B-RE-luc mouse study. JC, ZS, DR, AR, JR, and HK conducted the tumor studies in the SCID mice. HK and MP conducted the CDNB, DCNB, and NQO assays. RS conducted the statistical analyses. PA analyzed the tissues for histopathology. The manuscript was written by HK with the assistance of AR, DR, MJM, RS, and JC. All the authors have seen the manuscript and agree to its contents.

\section{Authors' information}

HK and JC are Associate professors (Ph.D.); RS is an Associate professor of Medicine (Ph.D.); MJM is a Professor (Ph.D.); PA is a Professor of Pathology (M.D.). ZS and DR were Ph.D. students during the study, and AR was a summer undergraduate intern. MP and JR are Research Associates/Lab Managers (B.S.).

\section{Competing interests}

The authors declare that they have no competing interests.

Received: 13 March 2010 Accepted: 26 July 2010

Published: 26 July 2010

\section{References}

1. Jemal A, Siegel R, Ward E, Hao Y, Xu J, Thun MJ: Cancer Statistics, 2009. CA Cancer J Clin 2009, 59(4):225-49.

2. Alam M, Ratner D: Cutaneous squamous-cell carcinoma. N Engl J Med 2001, 344(13):975-983.

3. Karin M: Nuclear factor-kappaB in cancer development and progression Nature 2006, 441(7092):431-436.

4. Aggarwal BB: Nuclear factor-kappaB: the enemy within. Cancer Cell 2004 6(3):203-208.

5. Kondo A, Ohigashi $\mathrm{H}$, Murakami A: A potent inhibitor of tumor promoterinduced Epstein-Barr virus activation, 1'-acetoxychavicol acetate from Languas galanga, a traditional Thai condiment. Bioscience Biotechnology Biochemistry 1993, 57:1344-1345.

6. Murakami A, Ohura S, Nakamura Y, Koshimizu K, Ohigashi H: 1'Acetoxychavicol acetate, a superoxide anion generation inhibitor potently inhibits tumor promotion by 12-0-tetradecanoylphorbol-13acetate in ICR mouse skin. Oncology 1996, 53(5):386-391.

7. Ichikawa H, Takada Y, Murakami A, Aggarwal BB: Identification of a novel blocker of I kappa B alpha kinase that enhances cellular apoptosis and inhibits cellular invasion through suppression of NF-kappa B-regulated gene products. J Immunol 2005, 174(11):7383-7392.

8. Murakami A, Kuki W, Takahashi Y, Yonei H, Nakamura Y, Ohto Y, Ohigashi H, Koshimizu K: Auraptene, a citrus coumarin, inhibits 12-Otetradecanoylphorbol-13-acetate-induced tumor promotion in ICR mouse skin, possibly through suppression of superoxide generation in leukocytes. Jpn J Cancer Res 1997, 88(5):443-452.

9. Jun DY, Kim JS, Park HS, Han CR, Fang Z, Woo MH, Rhee IK, Kim YH: Apoptogenic activity of auraptene of Zanthoxylum schinifolium toward human acute leukemia Jurkat $T$ cells is associated with ER stressmediated caspase- 8 activation that stimulates mitochondria-dependent or -independent caspase cascade. Carcinogenesis 2007, 28(6):1303-1313.

10. Yu L, Zhang DM: [Studies on chemical constituents from fruits of Paliurus ramosissimus]. Zhongguo Zhong Yao Za Zhi 2006, 31(24):2049-2052.

11. Murakami A, Ohigashi H: Cancer-preventive anti-oxidants that attenuate free radical generation by inflammatory cells. Biol Chem 2006, 387(4):387-392.

12. Kawabata K, Murakami A, Ohigashi $\mathrm{H}$ : Auraptene decreases the activity of matrix metalloproteinases in dextran sulfate sodium-induced ulcerative colitis in ICR mice. Biosci Biotechnol Biochem 2006, 70(12):3062-3065.

13. Kohno H, Suzuki R, Curini M, Epifano F, Maltese F, Gonzales SP, Tanaka T: Dietary administration with prenyloxycoumarins, auraptene and collinin, inhibits colitis-related colon carcinogenesis in mice. Int J Cancer 2006, 118(12):2936-2942.

14. Kuroyanagi K, Kang MS, Goto T, Hirai S, Ohyama K, Kusudo T, Yu R, Yano M, Sasaki T, Takahashi N, et al: Citrus auraptene acts as an agonist for PPARs and enhances adiponectin production and MCP-1 reduction in 3T3-L1 adipocytes. Biochem Biophys Res Commun 2008, 366(1):219-225.

15. Takahashi Y, Inaba N, Kuwahara S, Kuki W, Yamane K, Murakami A: Rapid and convenient method for preparing aurapten-enriched product from hassaku peel oil: implications for cancer-preventive food additives. J Agric Food Chem 2002, 50(11):3193-3196.

16. Clagett-Dame M, DeLuca HF: The role of vitamin A in mammalian reproduction and embryonic development. Annu Rev Nutr 2002, 22:347-381.

17. Maden $M$, Hind M: Retinoic acid, a regeneration-inducing molecule. Dev Dyn 2003, 226(2):237-244.

18. Love JM, Gudas L: Vitamin A, differentiation and cancer. Curr Opin Cell Biol 1994, 6(6):825-831

19. Chen L-C, De Luca LM: Retinoid effects on skin cancer. Skin Cancer: Mechanisms and human relevance Boca Raton: CRC PressMukhtar H 1994, 401-424.

20. Verma AK: Inhibition of both stage I and stage II mouse skin tumour promotion by retinoic acid and the dependence of inhibition of tumor promotion on the duration of retinoic acid treatment. Cancer Res 1987, 47(19):5097-5101.

21. Cheepala SB, Yin W, Syed Z, Gill JN, McMillian A, Kleiner HE, Lynch M, Loganantharaj R, Trutschl M, Cvek U, et al: Identification of the B-Raf/Mek/ Erk MAP kinase pathway as a target for all-trans retinoic acid during skin cancer promotion. Mol Cancer 2009, 8:27.

22. Syed Z, Cheepala SB, Gill JN, Stein J, Nathan CA, DiGiovanni J, Batra V, Adegboyega $\mathrm{P}$, Kleiner HE, Clifford JL: All-trans retinoic acid suppresses Stat3 signaling during skin carcinogenesis. Cancer Prevention Research 2009, 2:903-911.

23. Carlsen H, Moskaug JO, Fromm SH, Blomhoff R: In vivo imaging of NFkappa B activity. J Immunol 2002, 168(3):1441-1446.

24. Barwick T, Bencherif B, Mountz JM, Avril N: Molecular PET and PET/CT imaging of tumour cell proliferation using F-18 fluoro-L-thymidine: a comprehensive evaluation. Nucl Med Commun 2009, 30(12):908-917.

25. Martin SJ, Eisenbarth JA, Wagner-Utermann U, Mier W, Henze M, Pritzkow $\mathrm{H}$, Haberkorn $U$, Eisenhut M: A new precursor for the radiosynthesis of [18F]FLT. Nucl Med Biol 2002, 29(2):263-273.

26. Habig WH, Jakoby WB: Assays for differentiation of glutathione Stransferases. Methods Enzymol 1981, 77:398-405.

27. Kleiner HE, Vulimiri SV, Miller L, Johnson WH, Whitman CP, DiGiovanni J: Oral administration of naturally occurring coumarins leads to altered phase I and II enzyme activities and reduced DNA adduct formation by polycyclic aromatic hydrocarbons in various tissues of SENCAR mice. Carcinogenesis 2001, 22(1):73-82.

28. Bradford MM: A rapid and sensitive method for the quantitation of microgram quantities of protein utilizing the principle of protein-dye binding. Anal Biochem 1976, 72:248-254.

29. Habig WH, Pabst MJ, Jakoby WB: Glutathione S-transferases. The first enzymatic step in mercapturic acid formation. J Biol Chem 1974, 249(22):7130-7139. 
30. Prochaska HJ, Talalay P: Purification and characterization of two isofunctional forms of $\mathrm{NAD}(\mathrm{P}) \mathrm{H}$ : quinone reductase from mouse liver. $J$ Biol Chem 1986, 261(3):1372-1378.

31. Kawabata K, Tanaka T, Yamamoto T, Ushida J, Hara A, Murakami A, Koshimizu K, Ohigashi H, Stoner GD, Mori H: Suppression of Nnitrosomethylbenzylamine-induced rat esophageal tumorigenesis by dietary feeding of 1'-acetoxychavicol acetate. Jpn J Cancer Res 2000 91(2):148-155.

32. Nakamura $Y$, Murakami $A$, Ohto $Y$, Torikai $K$, Tanaka $T$, Ohigashi $H$ : Suppression of tumor promoter-induced oxidative stress and inflammatory responses in mouse skin by a superoxide generation inhibitor 1'-acetoxychavicol acetate. Cancer Res 1998, 58(21):4832-4839.

33. Tanaka T, Kawabata K, Kakumoto M, Makita H, Matsunaga K, Mori H, Satoh K, Hara A, Murakami A, Koshimizu K, et al: Chemoprevention of azoxymethane-induced rat colon carcinogenesis by a xanthine oxidase inhibitor, 1'-acetoxychavicol acetate. Jpn J Cancer Res 1997, 88(9):821-830.

34. Ohnishi M, Tanaka T, Makita H, Kawamori T, Mori H, Satoh K, Hara A, Murakami A, Ohigashi $H$, Koshimizu K: Chemopreventive effect of a xanthine oxidase inhibitor, 1'-acetoxychavicol acetate, on rat oral carcinogenesis. Jpn J Cancer Res 1996, 87(4):349-356.

35. Prince $M$, Li Y, Childers A, Itoh K, Yamamoto M, Kleiner HE: Comparison of citrus coumarins on carcinogen-detoxifying enzymes in Nrf2 knockout mice. Toxicol Lett 2009, 185(3):180-186.

36. Murakami A, Wada K, Ueda N, Sasaki K, Haga M, Kuki W, Takahashi Y, Yonei $\mathrm{H}$, Koshimizu $\mathrm{K}$, Ohigashi $\mathrm{H}$ : In vitro absorption and metabolism of a citrus chemopreventive agent, auraptene, and its modifying effects on xenobiotic enzyme activities in mouse livers. Nutr Cancer 2000, 36(2):191-199.

37. Hayes JD, Pulford DJ: The glutathione S-transferase supergene family: regulation of GST and the contribution of the isoenzymes to cancer chemoprotection and drug resistance. Crit Rev Biochem Mol Biol 1995, 30(6):445-600.

38. Surh YJ: Cancer chemoprevention with dietary phytochemicals. Nat Rev Cancer 2003, 3(10):768-780.

39. Yang J, Liao X, Agarwal MK, Barnes L, Auron PE, Stark GR: Unphosphorylated STAT3 accumulates in response to IL- 6 and activates transcription by binding to NFkappaB. Genes Dev 2007, 21(11):1396-1408.

40. Lee H, Herrmann A, Deng JH, Kujawski M, Niu G, Li Z, Forman S, Jove R,

Pardoll DM, Yu H: Persistently activated Stat3 maintains constitutive NFkappaB activity in tumors. Cancer Cell 2009, 15(4):283-293.

41. Homma S, Ishii Y, Morishima Y, Yamadori T, Matsuno Y, Haraguchi N, Kikuchi N, Satoh H, Sakamoto T, Hizawa N, et al: Nrf2 enhances cell proliferation and resistance to anticancer drugs in human lung cancer. Clin Cancer Res 2009, 15(10):3423-3432.

42. Wang XJ, Hayes JD, Henderson CJ, Wolf CR: Identification of retinoic acid as an inhibitor of transcription factor Nrf2 through activation of retinoic acid receptor alpha. Proc Natl Acad Sci USA 2007, 104(49):19589-19594.

43. Hu L, Miao W, Loignon M, Kandouz M, Batist G: Putative chemopreventive molecules can increase Nrf2-regulated cell defense in some human cancer cell lines, resulting in resistance to common cytotoxic therapies. Cancer Chemother Pharmacol 2010, 66(3):467-74.

44. Tan KP, Kosuge K, Yang M, Ito S: NRF2 as a determinant of cellular resistance in retinoic acid cytotoxicity. Free Radic Biol Med 2008, 45(12):1663-1673.

\section{Pre-publication history}

The pre-publication history for this paper can be accessed here: http://www.biomedcentral.com/1471-2407/10/394/prepub

\section{doi:10.1186/1471-2407-10-394}

Cite this article as: Kleiner-Hancock et al.: Effects of ATRA combined with citrus and ginger-derived compounds in human SCC xenografts. BMC Cancer 2010 10:394.

\section{Submit your next manuscript to BioMed Central and take full advantage of:}

- Convenient online submission

- Thorough peer review

- No space constraints or color figure charges

- Immediate publication on acceptance

- Inclusion in PubMed, CAS, Scopus and Google Scholar

- Research which is freely available for redistribution

Submit your manuscript at www.biomedcentral com/submit
Ciomed Central 